\title{
Mikro Kirletici Naproksenin Atık Sulardan Spirulina platensis ile Modifiye Edilmiş Kitosan-Polivinilalkol Biyokompozitleri ile Adsorpsiyonu
}

\author{
Didem SALOGLU* \\ Yalova Üniversitesi, Mühendislik Fakültesi, Kimya ve Süreç Mühendisliği Bölümü, Yalova \\ (ORCID ID: 0000-0003-0503-056X)
}

\begin{abstract}
$\ddot{O} z$
Endüstriyel atık suların içerdiği mikro ve makro kirlilikler önemli bir çevresel kirletici kaynak olarak karşımıza çıkmaktadır. Bu nedenle, sunulan çalışmada, anti-enflamatuvar ilaç etken maddesi olan naproksenin, Spirulina platensis (SP) ile modifiye edilmiş kitosan/polivinil alkol (KTS-PVA) biyokompoziti kullanarak atık sulardan adsorpsiyon yöntemiyle giderilmesi incelenmiştir. Farklı oranlarda SP içeren KTS-PVA-SP biyokompozit malzemelerin sentezlenmesi için gluteraldehit çapraz bağlayıcı olarak kullanılmış, KTS-PVA-SP biyokompozitleri, içersindeki SP oranı \%1-3 (ağırlık/ağırlık) oranlarda hazırlanmış ve tüm biyokompozitlerin karakterizasyonu TGA, SEM, optik mikroskop ve BET analizleri ile yapılmıştır. Adsorpsiyon ile atık sulardan naproksenin giderimine ait çeşitli izoterm modelleri uygulanmış ve sonuçlar değerlendirilmiştir.
\end{abstract}

Anahtar kelimeler: biyokompozit, adsorsiyon, naproksen.

\section{Micro Pollutant Naproxen Adsorption from Waste Water using Modified Chitosan-Poly (vinyl alcohol) with Spirulina platensis}

\begin{abstract}
The micro and macro pollutant content of industrial waste waters is an important source of environmental pollution. In the presenting study, the feasibility of using modified chitosan/poly(vinyl alcohol) (KTS-PVA) with Spirulina platensis (SP) as an adsorbent for adsorption of anti-inflammatory drug naproxen from waste water was investigated. KTS-PVA-SP biocomposites were synthesized using gluteraldehyde as a crosslinker, the biocomposites were reacted with different ratios of SP at 1-3\% (w/w) in KTS-PVA-SP and the biocomposites were characterized by TGA, SEM, optical microscobe and BET analysis. Adsorption isotherms were applied onto naproxen treatment from waste water and the results were discussed.
\end{abstract}

Keywords: biocomposite, adsorption, naproxen.

\section{Giriş}

Kimyasal kirleticilerden kaynaklanabilecek çevresel tehlikeler, uzun süredir bilim dünyasının ilgisini çekmektedir. Son yıllarda farmasötik ilaçlar, kozmetikler, yiyecek katkı maddeleri ve kişisel bakım ürünlerinin tüketimi ciddi olarak artmaktadır. Yeni teknolojilerin gelişmesiyle birlikte, farmasötiklerin kullanımından kaynaklanan mikro kirleticilerin çevredeki varlıkları ve bertarafı odaklı çalışmalar yoğun ilgi görmektedir. Atık sulardan mikro kirleticilerin giderilmesi işleminde adsorpsiyon prosesi uygun yöntemlerden biri olup; ilaç, gıda, boya, kimya, petrol vb. birçok endüstride oluşan atıkların yüksek verimle tutulabilmesi ve ucuz maliyetle geri kazanılabilmesi için yaygın olarak kullanılan bir yöntemdir $[1,2]$.

Adsorpsiyon, sıvı fazda çözünmüş halde bulunan komponentlerin katı bir adsorban yüzeyine tutunması olarak ifade edilir. Adsorpsiyon işlemi, fiziksel, kimyasal ve biyolojik arıtma proseslerinde

\footnotetext{
*Sorumlu yazar: didemsalogludertli@gmail.com
}

Geliş Tarihi: 11.09.2018, Kabul Tarihi: 18.03.2019 
karşımıza çıkmakta ve atık sulardaki kirleticilerin uygun bir adsorbana tutularak giderilmesi için sıklıkla kullanılmaktadır [3].

Adsorpsiyon katı-sıv1 ve katı-gaz fazları arasında gerçekleşmektedir. Katı-sıvı adsorpsiyonu, içme suyu ve atık su arıtımında önemli rol oynamaktadır. Atık su arıtımında kolay temin edilen ve atık sulardaki mikro ya da makro kirleticileri tutabilen özellikteki adsorbanlar kullanılır. Bu işlemde alümina, silika jel, gözenekliliği yüksek reçineler ve aktif karbon geleneksel adsorbanlar olarak görev almaktadır. Günümüzde ise sentetik ve/veya doğal polimerik maddelerin organik ve/veya inorganik katkı maddeleri ilavesi ile gözenekliliklerinin ve porozitelerinin arttırılması sonucunda adsorpsiyon işlemlerinde kullanılması ve yüksek verimde atık su arıtımına imkân sağlamaları yeni ve yenilikçi bir yaklaşım olarak karşımıza çıkmaktadır [3,4].

Adsorpsiyon izotermleri, adsorpsiyon mekanizmasını belirlemek amacıyla türetilmiş matematiksel modellerdir ve adsorban maddenin adsorblayacağı maddeyi hangi koşullarda adsorplayabileceği konusunda fikir vermektedirler. Adsorpsiyon işlemi süresince adsorban yüzeyinde biriken madde miktarı ile çözeltide kalan madde miktarı arasında dinamik bir denge meydana gelmekte ve denge halinde adsorplanan madde miktarının adsorban miktarı ile değişimi adsorpsiyon izoterm eşitlikleri ile ifade edilmektedir [3,5].

Sunulan bu çalışmada, Spirulina platensis ile modifiye edilmiş kitosan/polivinil alkol biyokompozitlerinin adsorban olarak kullanılması ile son yıllarda yaygın olarak karşımıza çıkan bir mikro kirletici olan naproksenin atık sulardan giderilmesi incelenmiştir. Yapılan deneysel çalışmalarda öncelikle Spirulina platensis üretilmiş, gluteraldehit ile çapraz bağlanmış KTS-PVA polimer karışımı içerisine farklı oranlarda ilave edilmiş ve yeni adsorban yüzeyler üretilmiştir. Yapılan adsorpsiyon denemelerinde optimum adsorban miktarı, biyokompozitler içersindeki optimum SP miktarı ve optimum pH değerleri belirlenmiş, elde edilen deneysel veriler kullanılarak adsorpsiyonu temsil eden izoterm denklemleri saptanmış ve izoterm parametrelerinin uygunlukları ayrıntılı olarak değerlendirilmiştir.

\section{Materyal ve Metot}

Kitosan (deasetilasyon derecesi: \%85, molekül ağırlığı: 100.000-300.000 Da), polivinil alkol (hidroliz derecesi: 87-89\%mol, molekül ağırlı̆ğ: 85.000-124.000) Sigma-Aldrich'den temin edilmiştir. Polimerler herhangi bir saflaştırma işemine tabii tutulmadan doğrudan kullanılmıştır. Asetik asit ve gluteraldehid Merck firmasından alınmıştır. Zarrouk besiyeri hazırlanması aşamasında kullanılan tüm tuzlar SigmaAldrich firmasında sağlanmıştır.

\subsection{Spirulina platensis Üretimi}

Sunulan çalışma kapsamında Spirulina platensis suşu, Yalova Üniversitesi, Kimya ve Süreç Mühendisliği Laboratuvarlarından sağlanmıştır. $121^{\circ} \mathrm{C}$ 'de 15 dakika otoklavlanmak sureti ile sterilize edilmiş sulu Zarrouk besiyeri içersine aşı olarak kullanılan Spirulina platensis kültürü $0,15 \mathrm{~g}$ kuru ağırlık/L olacak şekilde inokulum yapılmış, ortam sıcaklığ $25 \pm 1^{\circ} \mathrm{C}$ 'de sabitlenmiş, $100 \mu \mathrm{mol}$ foton $/ \mathrm{m}^{2} \mathrm{~s}$ 1şık şiddetinde sürekli aydınlatmanın sağlandığı, 2 L/dk'lık hava beslenmesiyle, 15 gün süre ile, karıştırmalı şekilde 2 L'lik bir biyoreaktörde üretilmiştir (Şekil 1). Deneysel çalışmalarda Spirulina platensis gelişimine ilişkin optik yoğunluk değerleri UV spektrofotometrede $680 \mathrm{~nm}$ 'de takip edilmiştir [6,7].

Biyoreaktörde üretilen Spirulina platensis'in KTS-PVA polimerik matriksine katk1 olarak kullanılabilmesi için, ürün öncelikle santrifüj işlemine tabii tutulmuştur. İçerdiği hava kabarcıkları sebebiyle santrifüj işlemi yetersiz kaldığından 1,2 $\mu \mathrm{m}$ gözenek açıklığına sahip filtre kağıdından vakum pompası yardımıyla filtre edilmiştir. Ardından filtrat $0.1 \mathrm{M}$ fosfat tamponu (pH 7.4) ile yıkanmış ve $90^{\circ} \mathrm{C}$ 'de etüvde kurutulmak suretiyle katı formda elde edilmiştir [7]. 


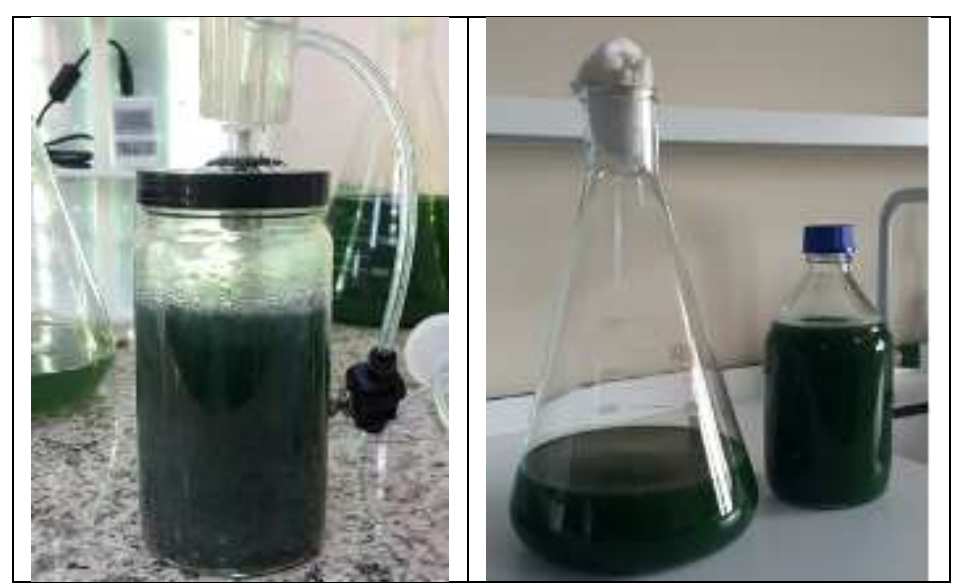

Şekil 1. Laboratuvar ortamında Spirulina platensis üretimi

\subsection{KTS-PVA ve KTS-PVA-SP Sentezi}

PVA, deiyonize suda $80^{\circ} \mathrm{C}^{\prime}$ de 1 sıtıcılı manyetik karıştırıcıda 4 saat karıştırılarak \%1'lik (ağırlık/hacim) PVA çözeltisi elde edilmiştir. KTS oda sıcaklığında \%2'lik seyreltik asetik asit ile 24 saat karıştırılarak KTS çözeltisi hazırlanmıştır. KTS ve PVA çözeltileri (1:1 (ağırlık/ağırlık)) birbiri içine homojen dağılmaları sağlanacak şekilde, $60^{\circ} \mathrm{C}$ 'de 12 saat karıştırılarak KTS-PVA blend yapısı oluşturulmuştur. \%1'lik glutaraldehit çözeltisi KTS-PVA çözeltisine çapraz bağlanma ajanı olarak ilave edilmiş ve çözelti viskoz hale gelene kadar oda sıcaklığında 1 saat karıştırılmıştır.

Naproksen gideriminde adsorban yüzey olarak kullanılan KTS-PVA-SP biyokompozitlerinin sentezi için, laboratuvar ortamında sentezlenmiş ve kurutulmuş Spirulina platensis \%1-3 (ağırlık/ağırlık) oranında saf KTS-PVA çözeltisi içine ilave edilmiş ve daha sonra çapraz bağlayıcı ilavesi yapılarak polimerik sistemin çapraz bağlanması sağlanmıştır. KTS-PVA-SP biyokompozitleri petri kabına alınarak kurutulmuş ve sentez aşaması tamamlanmıştır. KTS-PVA-SP sentezine ait şematik gösterim Şekil 2'de sunulmuştur $[8,9]$.

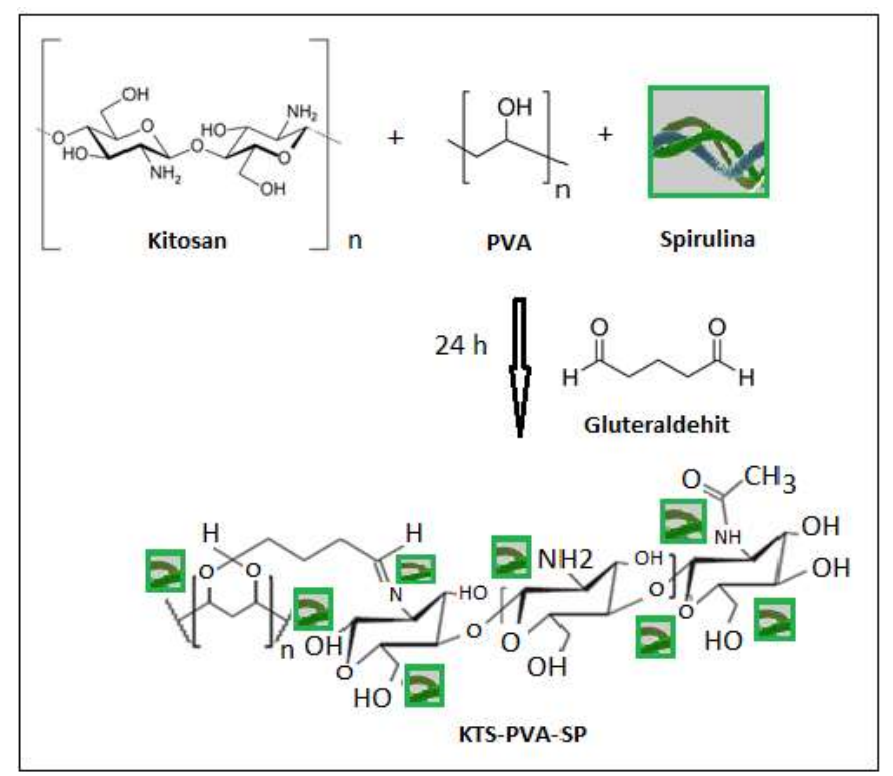

Şekil 2. Adsorban yüzey olarak kullanılan KTS-PVA-SP’nin sentez mekanizması

\subsection{KTS-PVA ve KTS-PVA-SP Karakterizasyonu}

KTS-PVA ve KTS-PVA-SP biyokompozitlerinin termal karakterizasyon analizleri Termogravimetrik analiz (Perkin Elmer, Diamond DSC) yöntemi ile saptanmıştır. 10-20 mg örnek oda sıcaklığından $800^{\circ} \mathrm{C}$ 'ye kadar $10^{\circ} \mathrm{C} /$ dakika hızla azot atmosferinde 1 sitılarak biyokompozit yapıların termal dayanımları 
saptanmıştır. Yüzey karakterizasyonu Optik mikroskop ve SEM (ESEM-FEG/EDAX Philips XL-30) ile tespit edilmiştir [9]. Ayrıca BET yüzey alan ölçümleri (Micromimeritics Flow 2) belirlenmiştir.

\subsection{Naproksen Mikro Kirleticisinin Adsorpsiyonu}

$50 \mathrm{mg} / \mathrm{L}$ naproksen konsantrasyonunda, farklı KTS-PVA-SP miktarları için, $25^{\circ} \mathrm{C}$ 'deki su banyosunda 140 rpm'de çalkalamalı olarak adsorpsiyon işlemleri yapılmış ve optimum adsorban miktarı belirlenmiştir. Aynı naproksen konsantrasyonu için naproksen çözeltisi pH'1 3.0-11.0 aralığında olacak şekilde 15-420 dakika aralığında adsorpsiyon çalışmaları yapılarak optimum pH değerleri saptanmıştır.

Yapılan optimizasyon çalışmaları sonucunda, $50 \mathrm{mg} / \mathrm{L}$ naproksen konsantrasyonu için $\mathrm{pH}$ 7.0'de, $25^{\circ} \mathrm{C}$ 'de, 300 dakika boyunca, $140 \mathrm{rpm}$ 'de, $100 \mathrm{mg}$ KTS-PVA-SP/(1-3) miktarları ile adsorpsiyon çalışmaları kesikli olarak gerçekleştirilmiş ve tüm KTS-PVA-SP biyokompozit çeşitleri için adsorpsiyon izotermleri çıkarılmıştır. Denge halindeki naproksen konsantrasyonu UV-Spektrofotometre ile $276 \mathrm{~nm}$ dalga boyunda tespit edilmiştir. Yapılan tüm deneysel çalışmalar iki tekrarlıdır ve ortalama sonuçlar adsorpsiyon izotermleri çalışmalarında kullanılmıştır [3,9].

\section{Bulgular ve Tartışma}

\subsection{KTS-PVA ve KTS-PVA-SP Karakterizasyonu}

KTS-PVA ve KTS-PVA-SP biyokompozit malzemelerinin TGA termogramları Şekil 3’te gösterilmiştir.

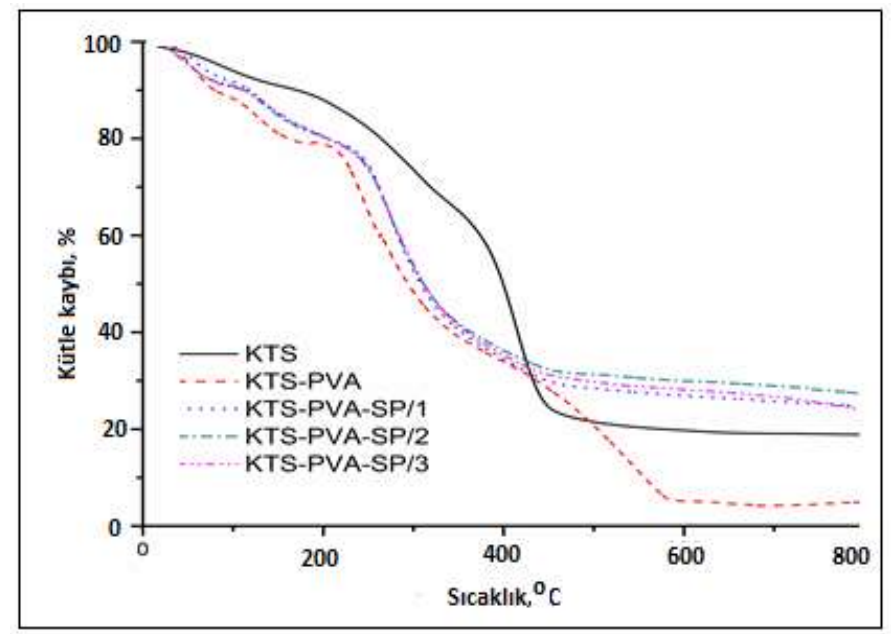

Şekil 3. Adsorban yüzey olarak kullanılan KTS-PVA ve KTS-PVA-SP biyokompozitlerinin TGA termogramları

TGA termogramları incelendiğinde, tüm biyokompozitlerin termal bozunmaya $100^{\circ} \mathrm{C}$ 'de başladığı görülmüştür. Saptanan bu kütle kaybı, yapıda bulunan mevcut suyun buharlaşmasından ve polimer zincirlerindeki uç grupların degradasyonundan kaynaklanmaktadır. Saf KTS ve KTS-PVA'nın $800^{\circ} \mathrm{C}^{\prime}$ ye kadar tüm SP katkılı biyokompozitlere oranla daha hızlı degrade olduğu açıktır. KTS-PVA $200^{\circ} \mathrm{C}$ 'de ve $400^{\circ} \mathrm{C}$ 'de olmak üzere 2 bozunma fazına sahiptir ve $400^{\circ} \mathrm{C}$ 'deki degradasyon PVA'nın bozunmasina aittir [9].

Şekil 3’te görüldüğü gibi KTS-PVA $600^{\circ} \mathrm{C}$ 'den önce mevcut kütlesinin $\% 95$ 'ini kaybetmiştir. SP ile modifiye edilmiş biyokompozitlerin termal bozunma hızlarının KTS-PVA'ya ve saf KTS'a oranla çok daha yavaş olduğu açıktır. $400^{\circ} \mathrm{C}$ 'den itibaren KTS-PVA-SP biyokompozitlerinin mevcut kütlerinin yaklaşık \%30'unun korunduğu izlenmiştir. Bu sonuç sentezlenen biyokompozitlerin tümünde Spirulina platensis katkısının KTS-PVA'ya oranla malzemenin termal stabilitesini fazlasıyla arttırdığını göstermektedir.

Şekil 4'de KTS-PVA ve KTS-PVA-SP biyokompozitlerine ait optik mikroskop ve SEM görüntüleri sunulmaktadır. Optik mikroskop sonuçlarına göre (Şekil 4a-d), KTS-PVA yüzeyinde etkin miktarda Spirulina platensis bulunduğu görülmektedir. SP oranı arttıkça yüzeyde gözlenen SP miktarında ve yapısında belirgin bir artış ve değişiklik mevcuttur. 
Optik mikroskoptan izlenen bu sonuçlara göre daha etkin bir yüzey morfolojisi incelemesi yapılması amacıyla, biyokompozitlerin SEM görüntüleri (Şekil 4e-h) izlenmiştir. KTS-PVA'nın yüzey morfolojisi incelendiğinde, yüzeye yayılmış halde agglomerik yapıda topaklanmalar ve bu topaklanmaların üzerinde 50-100 $\mu \mathrm{m}$ boyutlarında açık porlar izlenmiştir. KTS-PVA'nın bu yüzeyi; Spirulina platensis ile modifiye edilmesiyle birlikte, biyokompozit içinde artan SP miktarı ile artan oranda, boyutları yaklaşı 1-10 $\mu \mathrm{m}$ arasında olan por içinde por yapısı ile uyum gösteren, yer yer SP'nin KTS-PVA içine yerleşiminden kaynaklanan liflerin olduğu gözenekli bir hal almıştır. Bu yeni yapının oluşumunun KTS-PVA ile Spirulina platensis arasındaki fiziksel etkileşimlere bağlı olduğu öngörülmüştür.

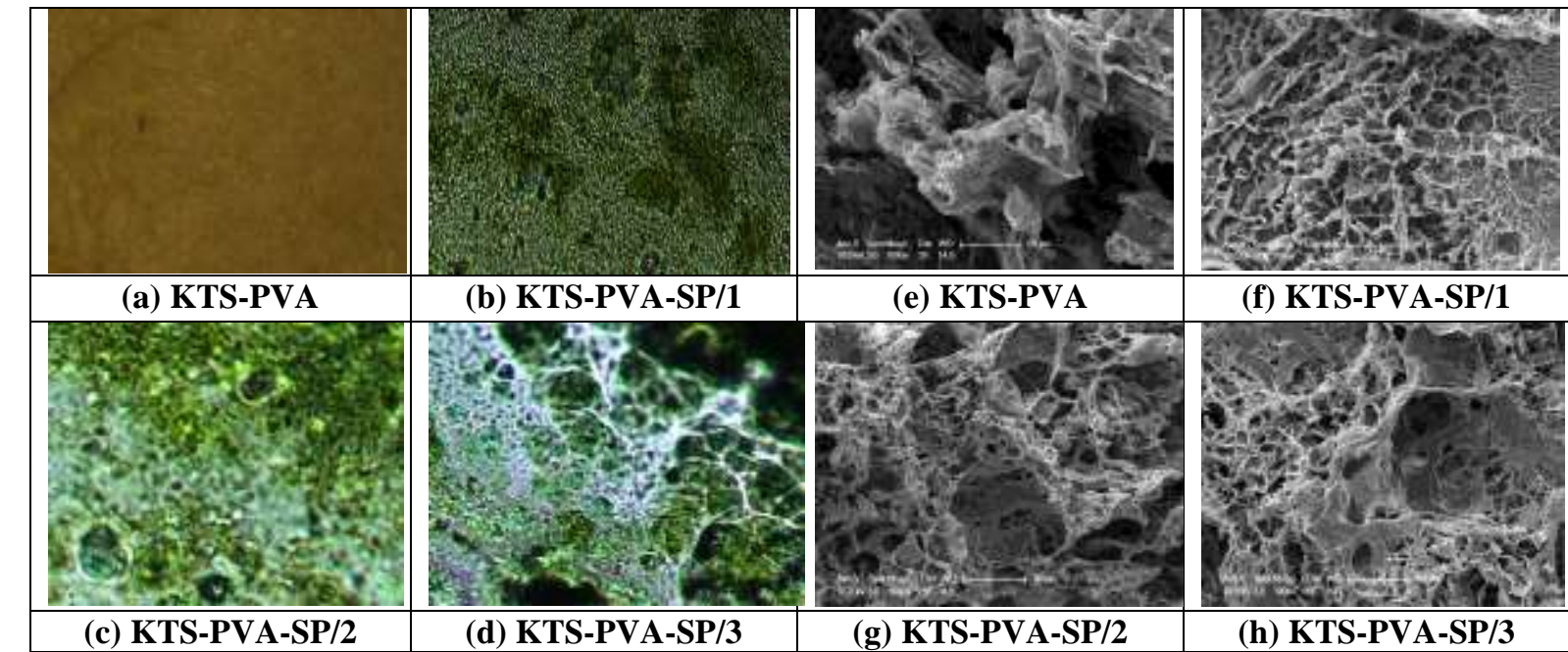

Şekil 4. Adsorban yüzey olarak kullanılan KTS-PVA ve KTS-PVA-SP biyokompozitlerinin optik mikroskop (a-d) ve SEM görüntüleri (e-h)

SEM ve optik mikroskop görüntülerinde saptanan poröz yapıdan yola çıkarak, biyokompozitlerin yüzey alanlarının ölçülmesine ilişkin BET analiz sonuçları incelendiğinde, SP'ye ait yüzey alanı $382 \mathrm{~m}^{2} / \mathrm{g}$ iken, yüzey alanı $66 \mathrm{~m}^{2} / \mathrm{g}$ olan KTS-PVA'ya \%1 (ağırlık/ağıllık) oranında SP ilave edilerek KTS-PVA$\mathrm{SP} / 1$ üretildiğinde, yüzey alanı $72 \mathrm{~m}^{2} / \mathrm{g}$ 'a çıkarken KTS-PVA-SP/3'ün yüzey alanı ise $128 \mathrm{~m}^{2} / \mathrm{g}$ 'a kadar artmıştır. Bu durum, SP'nin poröz ve gözenekli yapısının üretilen biyokompozitler için poroziteyi sağlayıcı parametre olarak kabul edilmesine sebeptir.

\subsection{KTS-PVA ve KTS-PVA-SP Biyokompozitleri ile Atık Sulardan Naproksen Adsorpsiyonu}

\subsubsection{Optimum Adsorban Miktarının Belirlenmesi}

SP, KTS-PVA ve KTS-PVA-SP biyokompozitleri ile naproksenin giderimi işleminde adsorban miktarının optimizasyonu için $50 \mathrm{mg} / \mathrm{L}$ naproksen başlangıç konsantrasyonu için 50-300 mg aralığında farklı miktarlarda adsorbanlar ile deneyler yapılmıştır. Adsorban miktarı arttıkça adsorpsiyon kapasite değerlerinde belirgin bir azalma görülmüştür (Şekil 5). Kapasite değerlerindeki bu azalma adsorban yüzeyindeki aktif bölgelerin naproksen ile doyurulamaması ile açıklanabilir [14].

Adsorban miktarının azalması ile adsorpsiyon kapasite değerlerinde etkin bir artış olması sebebiyle, çalışmanın ilerleyen kısımlarında $100 \mathrm{mg}$ adsorban ile çalışılmıştır. 


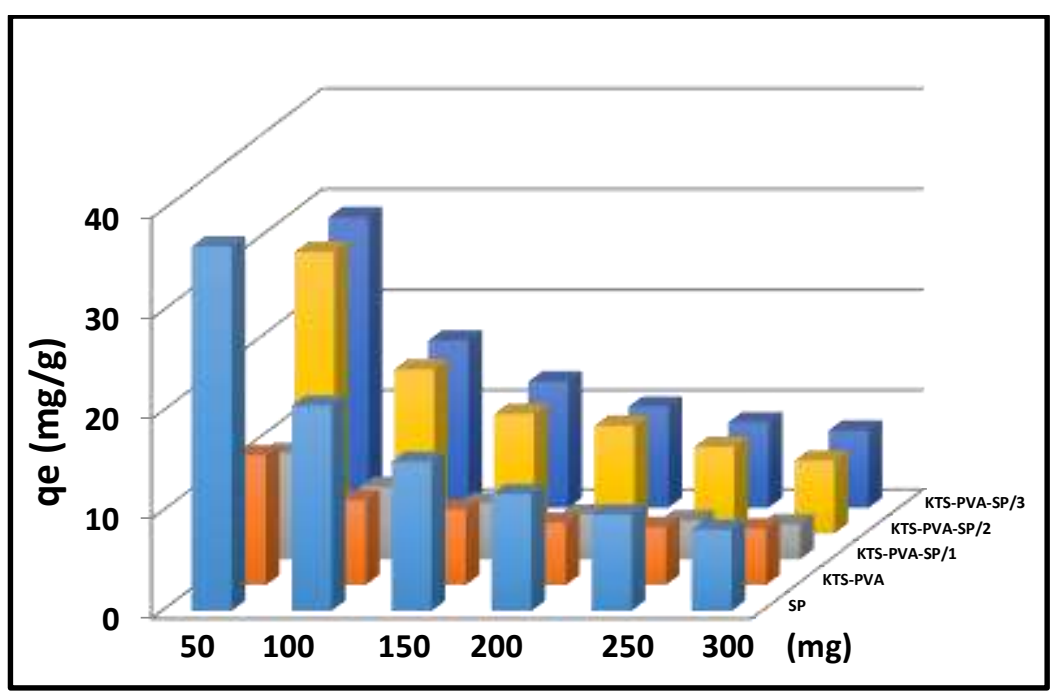

Şekil 5. Optimum adsorban miktarının belirlenmesi

\subsubsection{Biyokompozitlerin Yapısındaki Optimum SP Miktarının Belirlenmesi}

Yapılan deneysel çalışmaların sonucunda, $100 \mathrm{mg}$ adsorban ile yapılan naproksen adsorpsiyonunda adsorpsiyon yüzdesi değerleri Şekil 6'da sunulmuştur. Şekilden de açıkça görülebileceği gibi, SP ve KTS-PVA ile yapılan adsorpsiyon çalışmalarında adsorpsiyon yüzdeleri sırasıyla $\% 97$ ve $\% 68$ olarak saptanmıştır. SP'nin KTS-PVA polimerik yapısına katkı maddesi olarak ilave edilmesi ile elde edilen biyokompozitler, SP yapısıyla uyumlu olarak KTS-PVA'dan daha gözenekli, lifli ve poröz bir yapı olarak izlenmiştir (Şekil 4e-h). Bu nedenle sentezlenen biyokompozitlerin yapısındaki SP oranı arttıkça adsorpsiyon yüzdesi de etkin bir şekilde artmıştır. 100 mg KTS-PVA-SP/1, KTS-PVA-SP/2 ve KTSPVA-SP/3 biyokompozitleri ile $\mathrm{pH}$ 7.0'de yapılan adsorpsiyon işlemlerinde adsorpsiyon yüzdeleri sırasıyla \%84, \%87 ve \%93 olarak belirlenmiştir. SP içeren biyokompozitler ile yapılan çalışmalarda elde edilen sonuçlar göz önüne alındığında, en yüksek adsorpsiyon verimi KTS-PVA/SP-3 ile yapılan adsorpsiyon işlemlerinde elde edilmiştir.

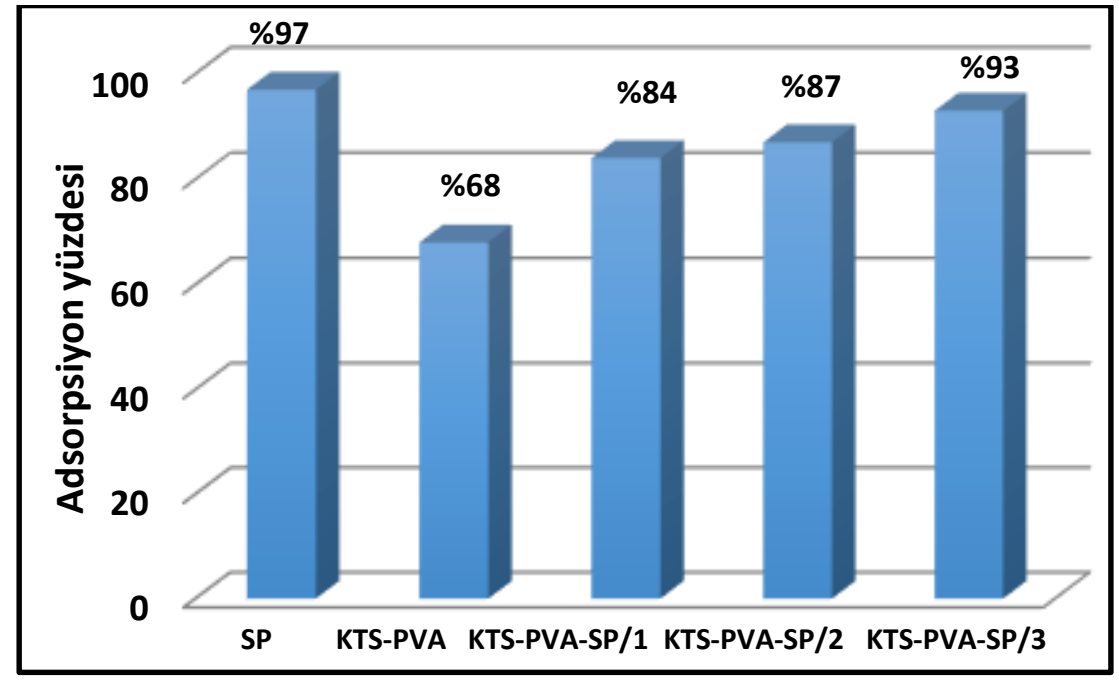

Şekil 6.100 mg adsorban kullanıldığında adsorpsiyon yüzdesi değerleri

\subsubsection{Optimum pH'ın Belirlenmesi}

$\mathrm{pH}$ değerinin adsorpsiyon işlemine etkisi Şekil 7'de görülmektedir. $\mathrm{q}_{\mathrm{e}}$ değerleri incelendiğinde, $\mathrm{pH}$ 3.0'den 11.0'e yükseldiğinde naproksen adsorpsiyonunda belirgin bir artış izlenmiştir. KTS-PVA-SP/3 kullanılarak yapılan adsorpsiyon çalışmalarında, $\mathrm{pH} 3.0$ 'de $\mathrm{q}_{\mathrm{e}}$ değeri 9,7 mg/g iken, $\mathrm{pH} 11.0$ 'de 14,0 mg/g'a yükselmiş ve pH 7.0, 9.0 ve 11.0 değerlerinde qe'nin sabit olduğu görülmüştür. Benzer şekilde, 
KTS-PVA-SP/1 ve KTS-PVA-SP/2 ile yapılan adsorpsiyon işlemlerinde $\mathrm{q}_{\mathrm{e}}$ değerleri $\mathrm{pH} 3.0$ için sırasıyla, $6,8 \mathrm{mg} / \mathrm{g}$ ve $7,8 \mathrm{mg} / \mathrm{g}$ ve $\mathrm{pH} 11.0$ için de $9.2 \mathrm{mg} / \mathrm{g}$ ve $11.0 \mathrm{mg} / \mathrm{g}$ olarak tespit edilmiştir.

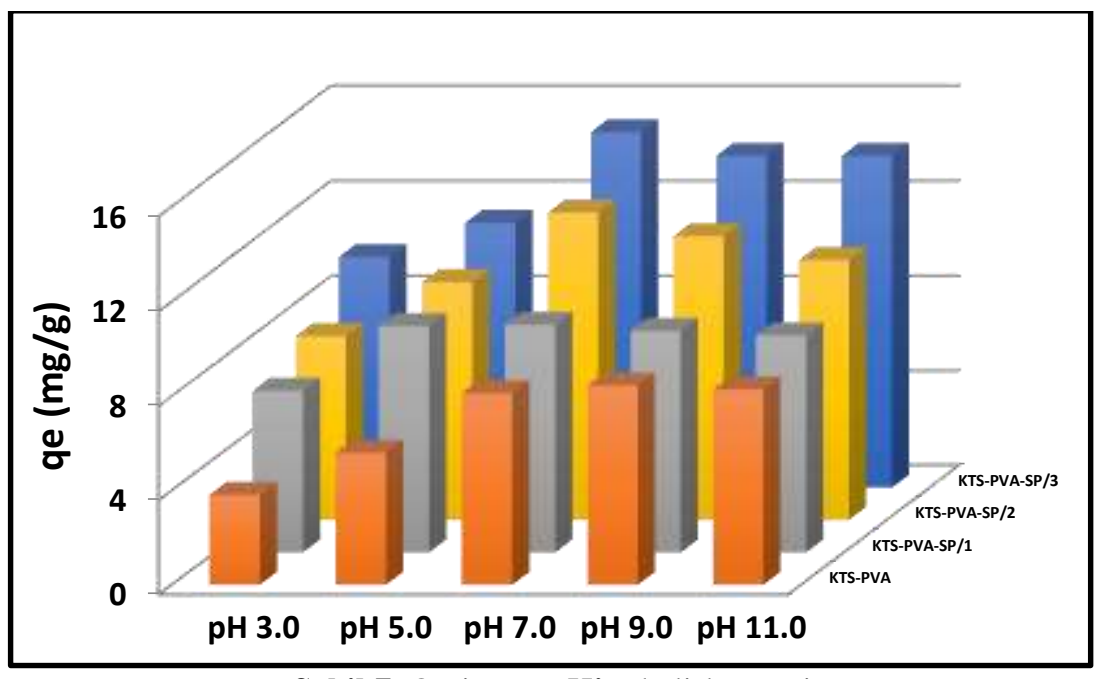

Şekil 7. Optimum pH'ın belirlenmesi

Şekil 7 incelendiğinde, $\mathrm{pH}$ 7.0'den sonrasında qe değerlerinde etkin bir değişiklik görülmemiştir. Daha önceki yayınlarımıza göre, CHT-PVA'ya ait yüzey $\mathrm{pH}$ değeri 4.5 'dur [8,9] ve naproksen üzerindeki -NH gruplarını ve buna bağlı olarak da naprokseni adsorplama kapasitesi pH 3.0-5.0 aralığı için düşük bir değerdir. SP katkılı biyokompozitler için ise, yüzey $\mathrm{pH}$ değeri 6.8 'e yükselmiştir ve bu değerin üzerindeki tüm $\mathrm{pH}$ değerlerinde naproksen üzerindeki katyonik gruplar elektrostatik kuvvetler nedeniyle çekilerek adsorpsiyon kapasitesini arttırmaktadır. $\mathrm{Bu}$ nedenle $\mathrm{pH} 7,0$ ve üzeri için adsorpsiyon kapasitesinin arttığı net olarak söylenebilir.

Sunulan çalışmada yapılan karakterizasyon ve optimizasyon sonuçları genel olarak değerlendirildiğinde, KTS-PVA polimerik yapısına eklenen SP ile sentezlenen biyokompozit yapıların, atık sulardan naproksen gideriminde etkin olarak kullanılabilir olduğu görülmüştür. Literatürdeki naproksen adsorpsiyonu ile yapılan çalışmalar incelendiğinde (Tablo 1), KTS-PVA-SP biyokompozitlerinin naproksen adsorpsiyonu için geleneksel adsorban yüzeylerle yarışır durumda olduğu sonucuna varılmıştır. Bu nedenle, sentezlenen biyokompozitler kullanılarak gerçekleştirilen naproksen adsorpsiyonuna ait mekanizmanın tespit edilebilmesi için çeşitli izoterm tipleri incelenmiş ve sonuçlar değerlendirilmiştir.

Tablo 1. Naproksen adsorpsiyonunda kullanilan adsorbanlar

\begin{tabular}{clcl}
\hline Mikrokirletici & \multicolumn{1}{c}{ Adsorban yüzey } & Adsorpsiyon yüzdesi & \multicolumn{1}{c}{ Referans } \\
\hline Naproksen & Kitosan-polivilalkol-humik asit & $\% 73$ & Kanmaz ve ark., 2019 [10] \\
Naproksen & Kitosan-polivilalkol-aktif karbon & $\% 97$ & Saloglu ve Ozcan, 2018[9] \\
Naproksen & Biyokok & $\% 97$ & Jung ve ark., 2015 $[11]$ \\
Naproksen & ACF (Aktif kabon fiber) & $\% 93$ & Ozdemir ve ark., 2012 [12] \\
Naproksen & Doğal kil & $\% 84$ & Khazri ve ark., 2017 [13] \\
Naproksen & Kitosan-polivilalkol-spirulina & $\% 93$ & Bu çalişma \\
\hline
\end{tabular}

\subsection{Adsorpsiyon İzotermlerinin Türetilmesi}

Adsorpsiyon mekanizmalarının tespit edilmesi amacıyla, $50 \mathrm{mg} / \mathrm{L}$ naproksen konsantrasyonu için $\mathrm{pH} 7.0$ değerinde, $25^{\circ} \mathrm{C}$ sıcaklıkta, 300 dakika boyunca, $140 \mathrm{rpm}$ çalkalama hızında, $100 \mathrm{mg}$ KTS-PVA-SP/(13) ile adsorpsiyon çalışmaları kesikli olarak gerçekleştirilmiş ve tüm biyokompozit çeşitleri için adsorpsiyon izotermleri çıkarılmıştır.

Freundlich izotermi: Freundlich eşitliği, adsorban yüzeyin heterojenliğini ve aktif kısımların dağılımını ve enerjilerini içeren bir ifadedir [15].

$\mathrm{q}_{\mathrm{e}}=\mathrm{K}_{\mathrm{f}} \mathrm{C}_{\mathrm{e}}^{1 / \mathrm{n}}$ 
Freundlich izotermindeki $\mathrm{K}_{\mathrm{f}}$, adsorpsiyon kapasite sabitini, $1 / \mathrm{n}$ ise yüzey heterojenliğini ve adsorpsiyonun şiddetini göstermektedir. $\mathrm{q}_{\mathrm{e}}$ birim adsorban miktarı üzerine adsorplanan madde miktarı $(\mathrm{mg} / \mathrm{g}), \mathrm{C}_{\mathrm{e}}$ ise denge halinde çözeltideki madde miktarıdır.

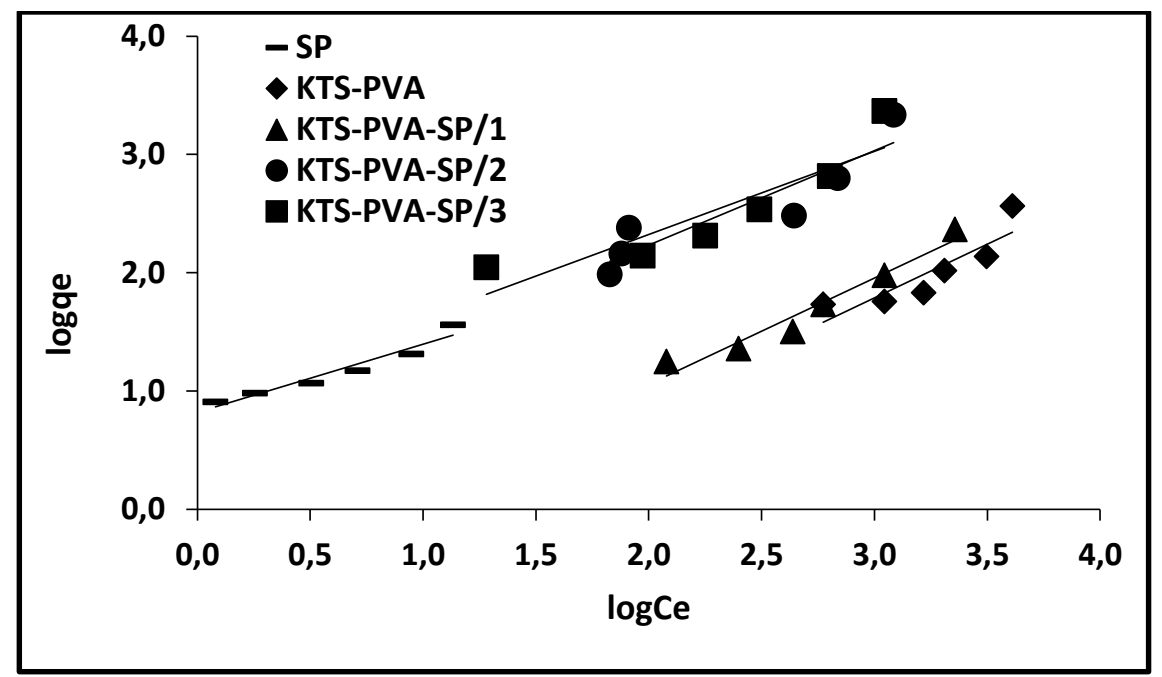

Şekil 8. Freundlich izotermi

Tüm biyokompozitler için $\mathrm{K}_{\mathrm{f}}$ ve $\mathrm{n}$ Freundlich izoterm sabitleri, Şekil 8'de görülen $\log \mathrm{C}_{\mathrm{e}}$ 'ye karş1 $\log q_{e}$ grafiğinin eğim ve kayım değerlerinden hesaplanmış ve Tablo 2'de sunulmuştur. $K_{f}$ adsorpsiyon kapasitesini ve adsorpsiyon bağının kuvveti ve $n$ ise heterojenliği ve dolayısıyla bağ dağılımını ifade etmektedir. $\mathrm{K}_{\mathrm{f}}$ ve $1 / \mathrm{n}$ değerleri ne kadar büyükse, adsorpsiyon kapasitesi de o kadar büyük olmaktadır $[16,17]$.

Tablo 2. Freundlinch adsorpsiyon izoterm sabitleri

\begin{tabular}{lcc}
\hline Biyokompozit & $\mathbf{n}$ & $\mathbf{K}_{\mathbf{f}}(\mathbf{L} / \mathbf{m g})$ \\
\hline SP & 1,85 & 6,61 \\
KTS-PVA & 1,11 & 2,50 \\
KTS-PVA-SP/1 & 1,12 & 2,07 \\
KTS-PVA-SP/2 & 1,25 & 1,89 \\
KTS-PVA-SP/3 & 1,42 & 2,48 \\
\hline
\end{tabular}

Tablo 2 incelendiğinde, $\mathrm{n}$ değerlerinin tüm biyokompozitler için, $1,11<\mathrm{n}<1,85$ aralığında değiştiği görülmektedir. n değerinin 1,0 'den büyük olmas1, biyokompozit yüzeyinin naproksen tarafından doyurulmuş olduğunu göstermektedir. Ayrıca, $1 / \mathrm{n}$ değeri, heterojenite faktörüdür ve $0,0-1,0$ aralığında değerler almakta ve adsorban yüzeyi ne kadar heterojense, $1 /$ n değeri o kadar 0,0 'a yakın olmaktadır. Bu izoterm, heterojen adsorpsiyon sistemlerinde Langmuir izotermine göre daha anlamlı sonuç vermektedir.

Dolayısıyla $n$ ve $1 / n$ değerlerine göre, SP yüzeyi daha heterojen bir yapıdadır ve bu yapıdaki adsorpsiyon kapasitesi diğer biyokompozitlere göre daha fazladır. KTS-PVA-SP/3 biyokompoziti diğer biyokompozitlerle karşılaştırıldığında, adsorpsiyon kapasitesi daha yüksek ve yüzey heterojenliği daha fazladır. Tüm biyokompozitler için Şekil 8'de yer alan doğruların regresyon katsayıları 0,81-0,93 aralığında olduğundan, Freundlich izotermi naproksen adsorpsiyonu için geçerlidir sonucuna varılabilir.

Langmuir izotermi: Langmuir izoterm modeli, homojen yüzeylerde gerçekleşen adsorpsiyon sistemlerine uygulanan, adsorban yüzeyinde eş enerjili ve sabit sayıda aktif bölgelerin mevcut olduğunu, adsorpsiyonun tek tabakalı olarak gerçekleştiğini ve maksimum adsorpsiyon kapasitesinin adsorban yüzeyindeki adsorplanan komponentlerin yüzeyde doygun bir tabaka oluşturduğu andaki adsorpsiyon kapasitesine eşit olduğu kabul eden bir metoddur.

$\frac{\mathrm{C}_{\mathrm{e}}}{\mathrm{q}_{\mathrm{e}}}=\frac{1}{\mathrm{q}_{\mathrm{m}} \mathrm{b}}+\frac{\mathrm{C}_{\mathrm{e}}}{\mathrm{q}_{\mathrm{m}}}$

b Langmuir izotermine ait afinite sabiti, $\mathrm{q}_{\mathrm{m}}$ ise maksimum adsorplama kapasitesidir ( $\left.\mathrm{g} / \mathrm{l}\right)$. 


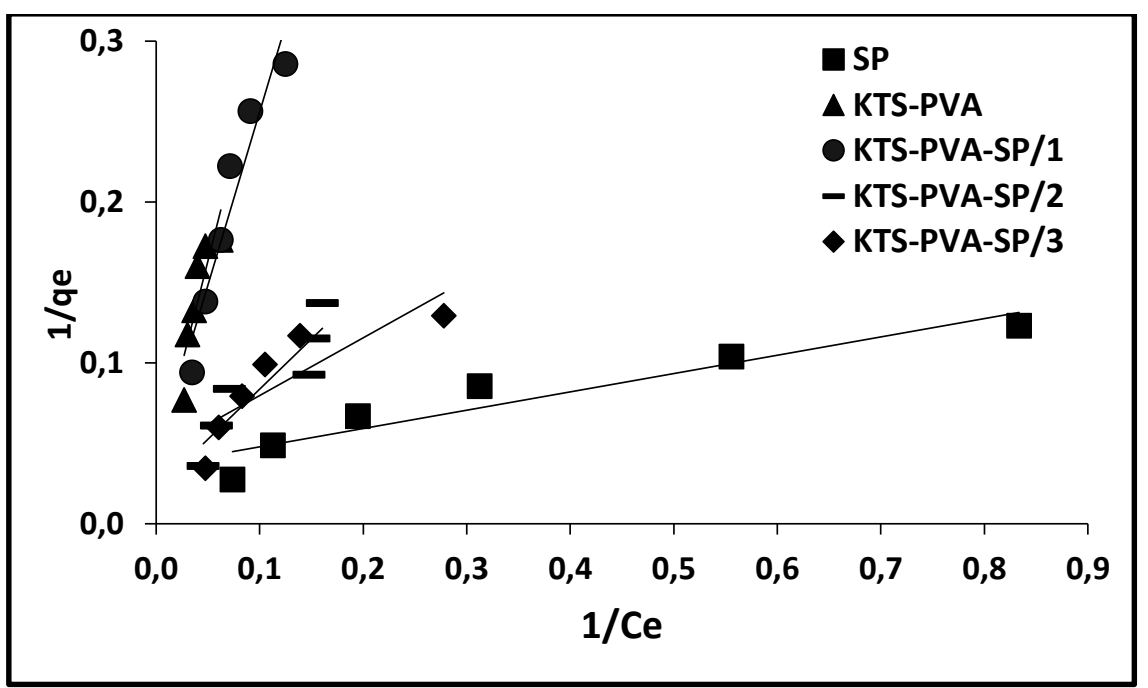

Şekil 9. Langmuir izotermi

Ayırma faktörü, $\mathrm{R}_{\mathrm{L}}$, izotermin tipi hakkında bilgi vermektedir. $\mathrm{R}_{\mathrm{L}}$ değeri 1,0 'den büyük ise adsorpsiyonun uygun olmadığının, $\mathrm{R}_{\mathrm{L}}$ değeri 1,0'den küçük ise adsorpsiyonun uygun olduğunun bir göstergesidir. $\mathrm{R}_{\mathrm{L}}$ değerinin 0,0 'a eşit olması ise adsorpsiyonun tersinmez olduğunu ifade ederken, $\mathrm{R}_{\mathrm{L}}$ değerinin sıfıra yaklaşması ideal tersinmez durumu göstermektedir [18].

Tablo 3. Langmuir adsorpsiyon izoterm sabitleri

\begin{tabular}{lccc}
\hline Biyokompozit & $\mathbf{q}_{\mathbf{m}}(\mathbf{m g} / \mathbf{L})$ & $\mathbf{b}$ & $\mathbf{R}_{\mathbf{L}}=\mathbf{1} /\left(\mathbf{1}+\mathbf{b C}_{\mathbf{0}}\right)$ \\
\hline SP & 50,0 & 0,031 & 0,39 \\
KTS-PVA & 23,0 & 0,119 & 0,14 \\
KTS-PVA-SP/1 & 25,0 & 0,018 & 0,52 \\
KTS-PVA-SP/2 & 27,7 & 0,319 & 0,05 \\
KTS-PVA-SP/3 & 28,6 & 0,013 & 0,60 \\
\hline
\end{tabular}

Şekil 9'da verilen grafikte $1 / C_{e}$ 'ye karş1 $1 / q_{e}$ değerlerine karş1 çizilen grafiğin eğim ve kayım değerlerinden $\mathrm{q}_{\mathrm{m}} \mathrm{ve} \mathrm{b}$ değerleri hesaplanmış ve Tablo 3 'te belirtilmiştir. Tabloda Langmuir izotermine ait $\mathrm{R}_{\mathrm{L}}$ değerleri de görülmektedir. SP için $\mathrm{R}_{\mathrm{L}}$ değeri 0,39 iken, KTS-PVA-SP/3 için 0,60 olarak saptanmıştır. Tüm biyokompozit tipleri için $R_{L}$ değeri değerleri $0,0<R_{L}<1,0$ aralığında olup, tümü 1,0 'den küçüktür ve bu durum, farklı SP oranları için adsorpsiyonun elverişli olduğunu gösterir. Ancak, Langmuir izoterm modeline göre hesaplanan $\mathrm{q}_{\mathrm{m}}$, deneysel çalışmalarla elde edilen $\mathrm{q}_{\mathrm{m}}$ değerlerinden belirgin bir sapma gösterdeğinden Langmuir izoterm modelinin naproksen giderimi için kullanılmasının uygun olmadığ 1 söylenebilir. Tüm biyokompozitleri için çizilen izoterm doğrularının $\mathrm{R}^{2}$ değerleri 0,71-0,89 aralığındadır. Regresyon katsayısı açısından da Freundlich ile mukayese edildiğinde, sistemin Freundlich izotermine daha uygun olduğu söylenebilir.

Temkin izotermi: Temkin izotermi, adsorpsiyon enerjisindeki azalmanın lineer gerçekleştiği kabulü ile uygulanmaktadır. Temkin izoterm denklemleri aşağıdaki gibidir.

$\mathrm{q}_{\mathrm{e}}=\frac{\mathrm{R} \cdot \mathrm{T}}{\mathrm{b}} \ln \left(\mathrm{A}_{\mathrm{T}} \cdot \mathrm{C}_{\mathrm{e}}\right)$

ve denklemin sadeleştirilmiş hali;

$\mathrm{q}_{\mathrm{e}}=\mathrm{B}_{\mathrm{T}} \ln \mathrm{A}_{\mathrm{T}}+\mathrm{B}_{\mathrm{T}} \ln \mathrm{C}_{\mathrm{e}}$

$\mathrm{A}_{\mathrm{T}}$ Temkin izoterm sabiti, $\mathrm{B}_{\mathrm{T}}$ 1S1 adsorplama kapasitesi, R; gaz sabiti (J/mol K) ve T mutlak sıcaklık (K)'dir. 
Şekil 10'da verilen grafiğin eğim ve kayım değerlerinden hesaplanan ve Tablo 4'de sunulan $\mathrm{A}_{\mathrm{T}}$ ve $B_{T}$ değerleri sırasıyla, SP için 2,5 ve 11,8; KTS-PVA-SP/1 için 8,5 ve 7,54 ve KTS-PVA-SP/3 için ise, 3,3 ve 10,3 olarak hesaplanmıştır.

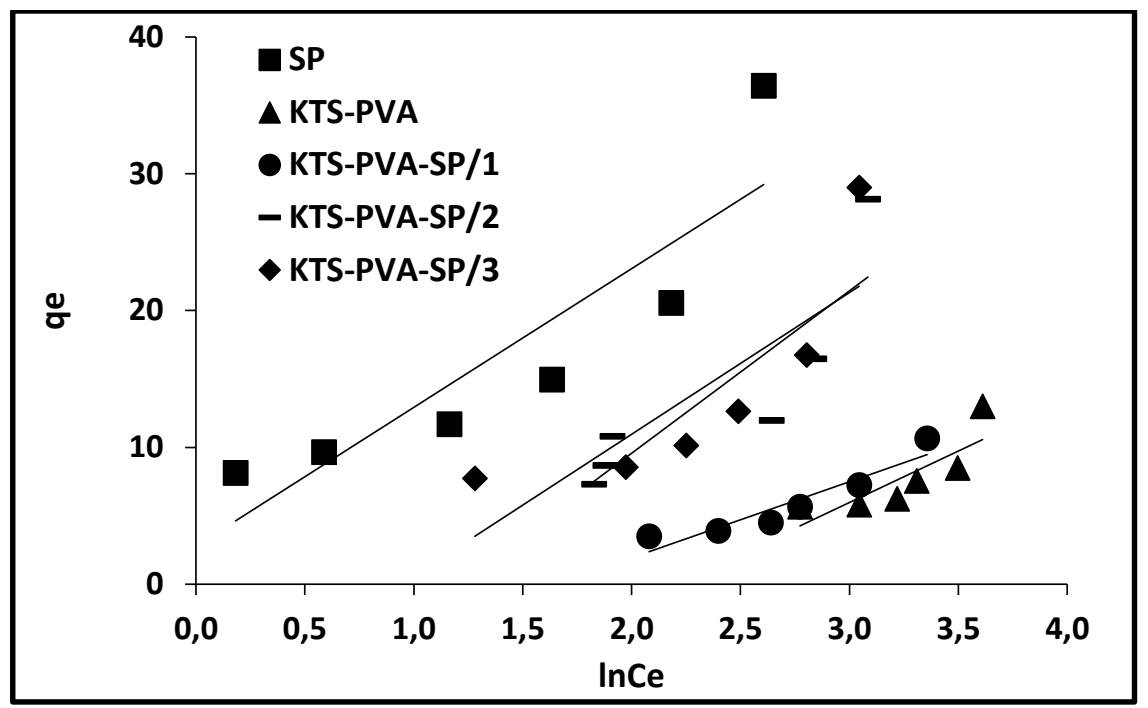

Şekil 10.Temkin izotermi

Şekil 10 ve Tablo 4'deki sabitlerden görüldüğü gibi, biyokompozitlerin yapısındaki SP'nin oranı arttıkça, 1sı absorplama kapasitesi de artmıştır [19].

Tablo 4. Temkin adsorpsiyon izoterm sabitleri

\begin{tabular}{lll}
\hline Biyokompozit & $\mathbf{A}_{\mathbf{T}}$ & $\mathbf{B}_{\mathbf{T}}$ \\
\hline SP & 2,5 & 11,8 \\
KTS-PVA & 5,2 & 5,56 \\
KTS-PVA-SP/1 & 8,5 & 7,54 \\
KTS-PVA-SP/2 & 1,3 & 10,1 \\
KTS-PVA-SP/3 & 3,3 & 10,3 \\
\hline
\end{tabular}

Tüm biyokompozitler için çizilen Temkin izoterm denklemlerindeki regresyon katsayıları 0,670,79 aralığında olup kabul edilebilirlik sınırları içindedir. Dolayısıyla, naproksen adsorpsiyonunda adsorpsiyon enerjisindeki azalmanın lineer gerçekleştiği söylenebilir.

Dubinin-Radushkevic (D-R) izotermi: Diğer izoterm modellerinden hesaplanan izoterm sabitleri, adsorpsiyon prosesine ait enerji özellikleri hakkında bilgi vermezken, Dubinin-Radushkevic (DR) izotermi, adsorplama enerjisi ve adsorpsiyonun spesifik özellikleri hakkında bilgi verme niteliğine sahiptir. Ayrıca, D-R izotermi aynı tip gözenekli yüzeylerde meydana gelen adsorplama işlemlerini açıklamak için kullanılabilir [19,20].

(5) no'lu eşitlikle açıklanan D-R izoterm modeli aşağıdaki ifade ile gösterilir.

$\ln \mathrm{q}_{\mathrm{e}}=\ln \mathrm{q}_{\mathrm{m}}-\mathrm{k} \varepsilon^{2}$

Denklemde $\varepsilon=R T \ln \left(1+1 / \mathrm{C}_{\mathrm{e}}\right)$ olarak ifade edilebilir. $\mathrm{C}_{\mathrm{e}}$ adsorpsiyon sonrası çözeltide kalan maddenin derişimi $(\mathrm{mg} / \mathrm{L}), \varepsilon$ polanyi potansiyeli, $\mathrm{q}_{\mathrm{m}}$ maksimum adsorplama kapasitesi $(\mathrm{g} / \mathrm{l})$ ve $\mathrm{k}$ ise $\mathrm{D}-\mathrm{R}$ izotermi sabitidir.

Şekil 11'den elde edilen eğim ve kayım değerlerinden hesaplanan ortalama serbest adsorpsiyon enerjileri SP için $745 \mathrm{kj} / \mathrm{mol}$ iken, KTS-PVA-SP/2 ve KTS-PVA-SP/3 için sırasıyla $158,1 \mathrm{ve} 223,6 \mathrm{kj} / \mathrm{mol}$ olarak bulunmuş ve değerler Tablo 4'de sunulmuştur. Tablo 5'deki aktivasyon enerjileri incelendiğinde, biyokompozit içerisinde artan SP oranı ile aktivasyon enerjilerinin de arttığ1 görülmüsstür. $\mathrm{R}^{2}$ değerleri 0,61-0,87 aralığında olduğundan, \%97'lik regresyon katsayısına sahip olan KTS-PVA-SP/3 için, diğer biyokompozitlere oranla gözeneklerin uniform olduğu ve adsorpsiyon işleminin en yüksek enerji ile meydana geldiği söylenebilir. 


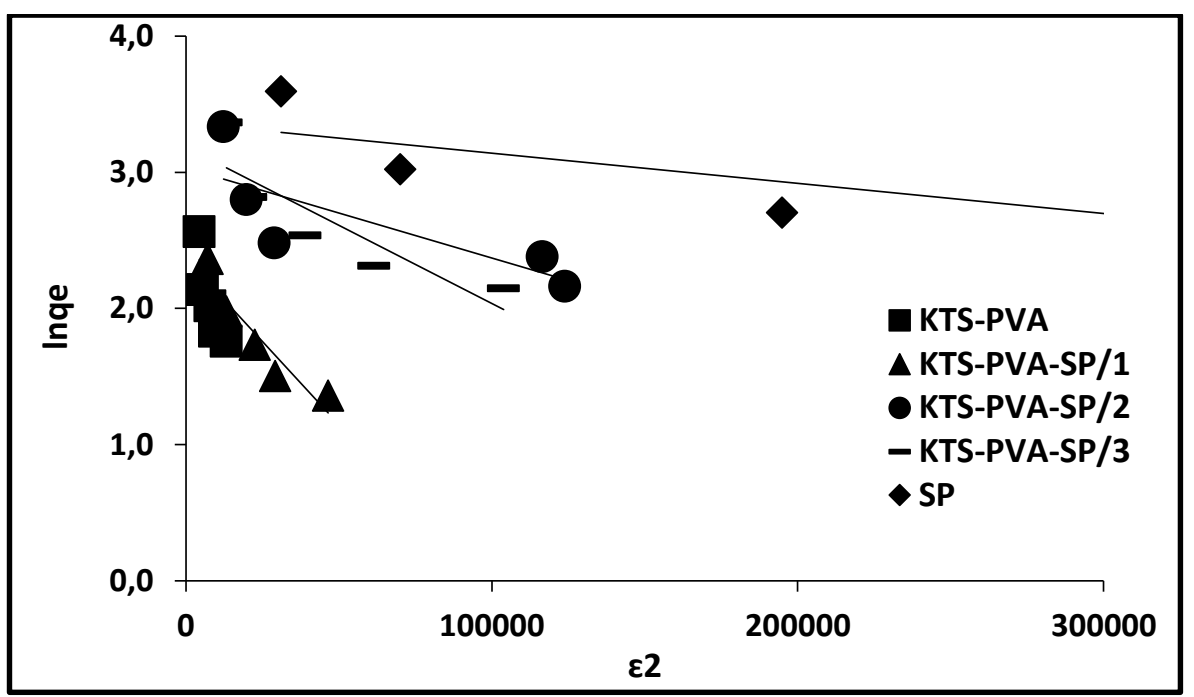

Şekil 11. D-R izotermi

Tablo 5. D-R adsorpsiyon izoterm sabitleri

\begin{tabular}{lccc}
\hline Biyokompozit & $\mathbf{q m}(\mathbf{m o l} / \mathbf{g})$ & $\mathbf{k x 1 0}^{-\mathbf{7}}$ & $\mathbf{E}=\mathbf{1 / ( 2 k})^{\mathbf{1 / 2}}$ \\
\hline SP & 23,1 & 9 & 745,3 \\
KTS-PVA & 14,8 & 8 & 79,1 \\
KTS-PVA-SP/1 & 10,7 & 7 & 84,5 \\
KTS-PVA-SP/2 & 20,7 & 2 & 158,1 \\
KTS-PVA-SP/3 & 24,0 & 1 & 223,6 \\
\hline
\end{tabular}

Janovich İzotermi: Janovich denklemi Langmuir izotermine benzer özellik gösteren tek tabakalı bir adsorpsiyon işlemini tanımlar.

$\mathrm{q}_{\mathrm{e}}=\mathrm{q}_{\mathrm{m}}\left(1-\mathrm{e}^{\mathrm{KjCe}}\right)$

lnqe değerlerine karşı $C_{e}$ değerlerinden elde edilen grafiğgin eğim ve kayım değerlerinden sırasıyla $\mathrm{K}_{\mathrm{J}}$ Janovich sabiti ve $\mathrm{q}_{\mathrm{m}}(\mathrm{mg} / \mathrm{L})$ maksimum adsorpsiyon kapasitesi hesaplanır [20].

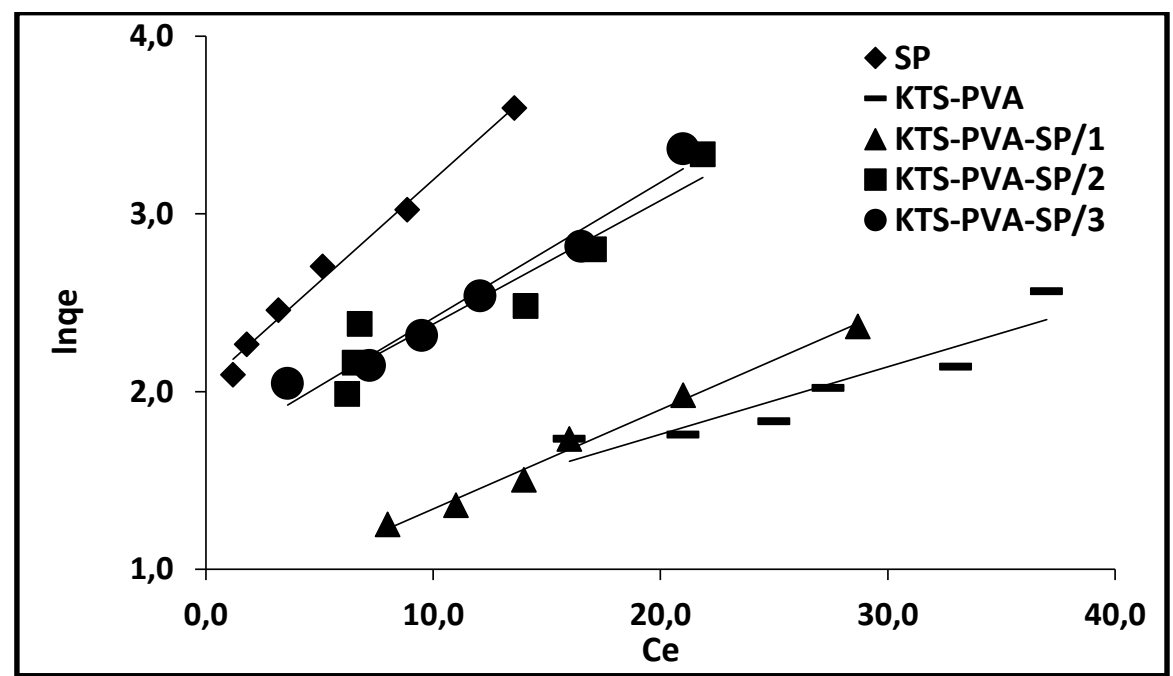

Şekil 12. Janovich izotermi

Şekil 12'de görülen eğim ve kayım değerlerinden Janovich sabitleri ve $\mathrm{q}_{\mathrm{m}}$ değerleri hesaplandığında, maksimum adsorpsiyon kapasite değerleri SP için 17,3 mg/L, KTS-PVA-SP/1 için 0,41 $\mathrm{mg} / \mathrm{L}$ ve KTS-PVA-SP/3 için 1,0 mg/L olarak hesaplanmıştır (Tablo 6). 
Tablo 6. Janovich adsorpsiyon izoterm sabitleri

\begin{tabular}{lcc}
\hline Biyokompozit & $\mathbf{K}_{\mathbf{j}}$ & $\mathbf{q m}(\mathbf{m g} / \mathbf{L})$ \\
\hline SP & 1,53 & 17,3 \\
KTS-PVA & 2,17 & 4,69 \\
KTS-PVA-SP/1 & 1,17 & 0,41 \\
KTS-PVA-SP/2 & 0,35 & 0,04 \\
KTS-PVA-SP/3 & 1,06 & 1,00 \\
\hline
\end{tabular}

Janovich izoterminden hesaplanan $\mathrm{q}_{\mathrm{m}}$ değerlerinin deneysel sonuçlardan elde edilen maksimum adsorpsiyon kapasitelerinden son derece farklı olması nedeniyle Janovich izotermi bu sistem için uygun değildir. Bu sonuç Langmuir izoterm modelinin Freundlich'e göre daha az uygun olarak belirlenmesi ile de birbirini doğrular niteliktedir.

Harkins-Jura izotermi: Harkins - Jura izotermi, çok tabakalı adsorpsiyonu, heterojen gözenek dağılımının varlığına bağlı olarak açıklar ve aşağıdaki şekilde ifade edilir:

$\frac{1}{\left(\mathrm{q}_{\mathrm{e}}\right)^{2}}=\left(\frac{\mathrm{B}_{\mathrm{H}}}{\mathrm{A}_{\mathrm{H}}}\right)-\left(\frac{1}{\mathrm{~A}_{\mathrm{H}}}\right) \log \mathrm{C}_{\mathrm{e}}$

$\log C_{e}$ değerleri, $1 / \mathrm{q}_{\mathrm{e}}^{2}$ değerlerine karşıl1k grafik çizildiğinde, eğim ve kayım değerinden $\mathrm{A}_{\mathrm{H}}$ ve $\mathrm{B}_{\mathrm{H}}$ Harkins - Jura sabitleri elde edilir. $\mathrm{B}_{\mathrm{H}}$ sabitinin büyüklüğü, adsorpsiyonda fiziksel adsorpsiyonun daha fazla olduğunu gösterir [20].

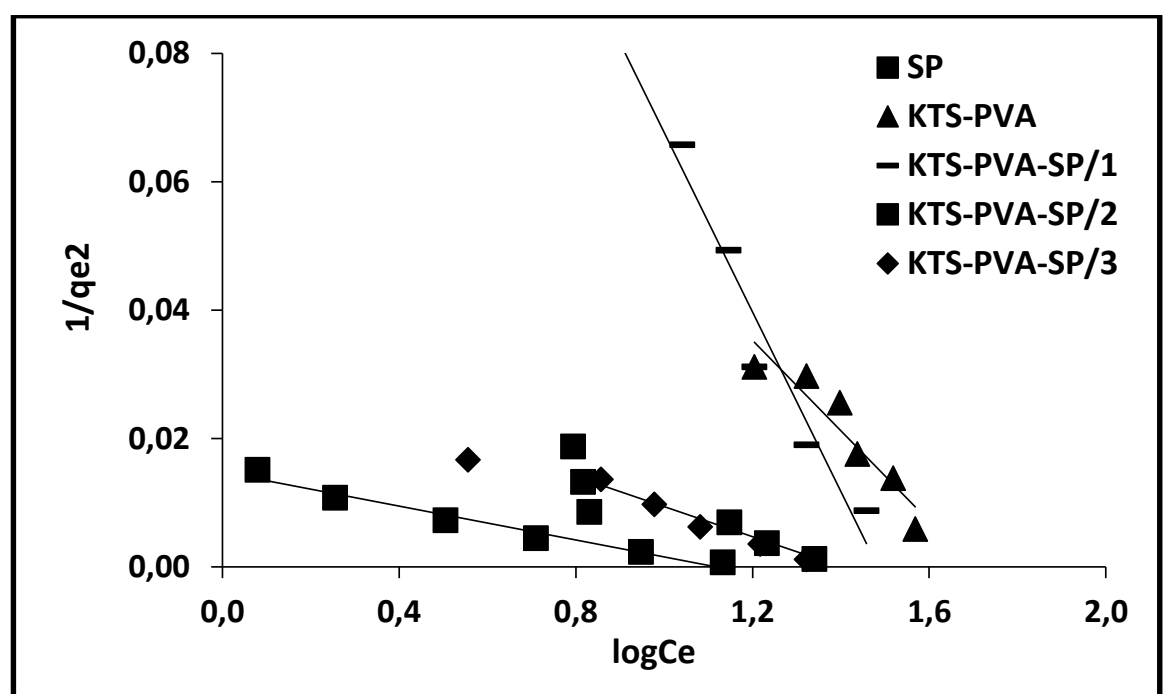

Şekil 13. Harkins-Jura izotermi

Harkins-Jura sabiti olan $\mathrm{B}_{\mathrm{H}}$ değerleri 1,12 -1,69 aralığında değişmektedir (Tablo 7).

Tablo 7. Harkins-Jura adsorpsiyon izoterm sabitleri

\begin{tabular}{lll}
\hline Biyokompozit & $\mathbf{A}_{\mathbf{H}}$ & $\mathbf{B}_{\mathbf{H}}$ \\
\hline SP & 75,7 & 1,12 \\
KTS-PVA & 14,2 & 1,69 \\
KTS-PVA-SP/1 & 7,11 & 1,45 \\
KTS-PVA-SP/2 & 42,7 & 1,36 \\
KTS-PVA-SP/3 & 46,7 & 1,35 \\
\hline
\end{tabular}

Aynı mertebede olan $\mathrm{B}_{\mathrm{H}}$ değerleri tüm biyokompozitler için adsorpsiyon işleminin fiziksel olarak gerçekleştiği söylenebilir. Ayrica tüm biyokompozitler için Harkins-Jura izotermlerine ait regresyon katsayıları 0,78-0,96 aralığında olduğundan, matematiksel olarak izoterm geçerlidir.

Halsey İotermi: Halsey izoterm denklemi (8) no'lu eşitlikle ifade edilir.

$\ln \mathrm{q}_{\mathrm{e}}=\left[\left(\frac{1}{\mathrm{n}}\right) \ln \mathrm{K}\right]-\left(\frac{1}{\mathrm{n}}\right) \ln \mathrm{C}_{\mathrm{e}}$ 
Halsey izoterm modelinden çok tabakalı ve düzensiz gözenekli yapıların varlığında bahsedilebilir $[19,20]$.

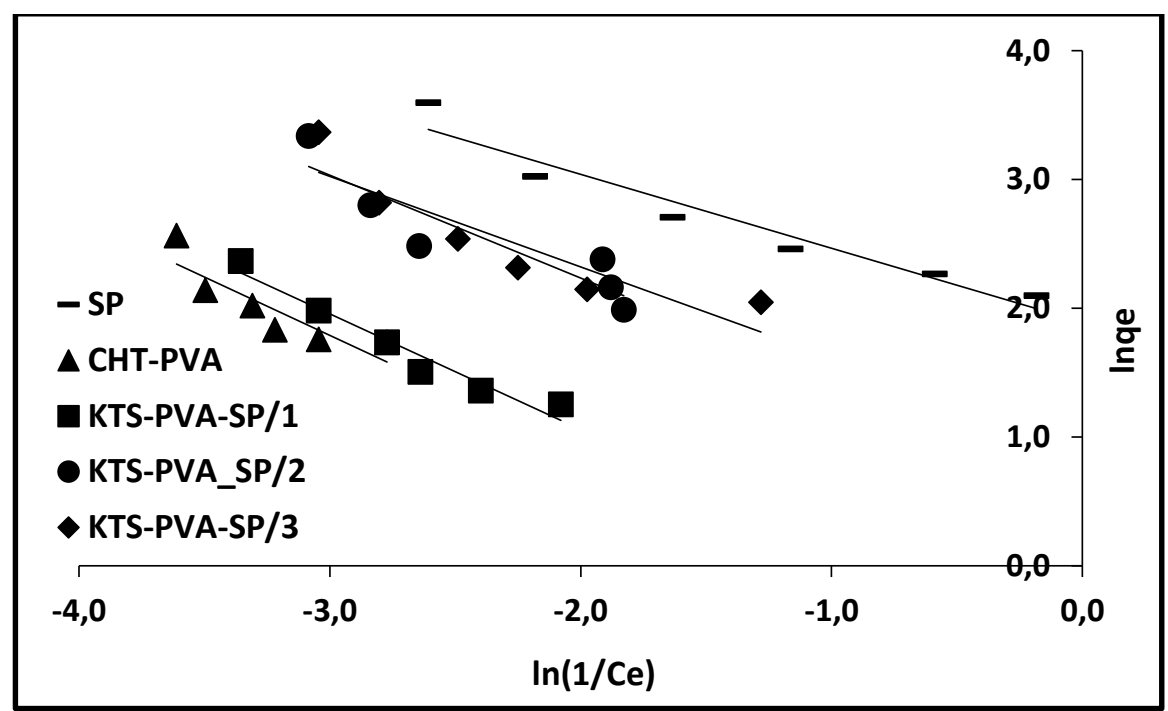

Şekil 14. Halsey izotermi

Şekil 14'de görülen eğim ve kayım değerlerinden hesaplanan n sabiti, SP için 1,75 iken KTSPVA-SP/2 ve KTS-PVA-SP/3 için sırasılla 1,26 ve 1,42 olarak belirlenmiştir (Tablo 8). Bu durum gözenekli olan biyokompozitlerin kullanıldığı adsorpsiyon işleminin, biyokompozit içindeki SP oranı arttıkça daha şiddetli olduğunu ve adsorpsiyonun 1s1 alan bir işlem olduğunu göstermektedir. Halsey izotermlerine ait regresyon katsayıları 0,77-0,93 aralığındadır ve bu oranlar da izotermin uygunluğunu ifade eder.

Tablo 8. Halsey adsorpsiyon izoterm sabitleri

\begin{tabular}{lrc}
\hline Biyokompozit & $\mathbf{n}$ & $\mathbf{K}$ \\
\hline SP & 1,75 & 0,07 \\
KTS-PVA & 1,11 & 0,18 \\
KTS-PVA-SP/1 & 1,12 & 0,42 \\
KTS-PVA-SP/2 & 1,26 & 0,67 \\
KTS-PVA-SP/3 & 1,42 & 0,44 \\
\hline
\end{tabular}

Çalışmada incelenen tüm izoterm modelleri ve izoterm parametreleri değerlendirildiğinde, KTSPVA-SP biyokompozitleri kullanılarak gerçekleştirilen naproksen adsorpsiyon mekanizması, temel olarak Freundlich izoterm modeline uygunluk göstermektedir. Bu modele göre, biyokompozit yapılar içindeki SP oranı arttıkça heterojenlik ve gözeneklilik artmıştır. KTS-PVA-SP/3'nin diğer biyokompozitlerle mukayese edildiğinde adsorpsiyon kapasitesinin en yüksek ve yüzey heterojenliğinin de daha fazla olduğu görülmüştür. Halsey, Temkin ve D-R modelleri de Freundlich izoterm modeliyle paralellik taşımakta ve bu üç izoterm modeli de biyokompozitlerin gözenekli yüzeylerinde meydana gelen adsorpsiyonun çok tabakalı olduğunu ve sistemin 1sı absorplama kapasitesinin arttığını göstermekte ve birbirini desteklemektedir. Harkins-Jura izotermi, naproksen adsorpsiyonunun fiziksel olarak gerçekleştiğini söylemektedir. Langmuir ve Janovich izoterm modellerindeki $\mathrm{q}_{\mathrm{m}}$ değerlerindeki sapmalar bu iki izoterm modeli için uyumsuzluk olarak belirlenmiştir.

\section{Sonuç ve Öneriler}

Bu çalışmada, son yıllarda pek çok atık su kaynağında yüksek oranda tespit edilen mikro kirleticilerden biri olan naproksenin, Spirulina platensis ile modifiye edilmiş kitosan/polivinil alkol biyokompozitleri ile giderilmesi ve biyokompozitlerin atık su arıtımındaki etkinliğinin incelenmesi esas alınmıştır. Yapılan deneysel çalışmalar sonucunda adsorpsiyon izotermleri oluşturularak, sistemin fiziksel ve kimyasal özellikleri ile adsorpsiyon mekanizmasının karakteristiği belirlenmiştir. Naproksenin KTS-PVA-SP biyokompozitleri ile adsorpsiyonunun, heterojen yüzeylerde çok tabakalı olarak fiziksel bağlanma ile 
gerçekleşen bir mekanizmaya sahip olduğu görülmüştür. Biyokompozitlerin yapısındaki SP oranı arttıkça naproksenin bağlanma enerjisinin arttığı ve adsorpsiyon kapasitesinin de buna paralel olarak yükseldiği izlenmiştir.

Sunulan çalışma kapsamında tartışılan sonuçlar göstermektedir ki, Spirulina platensis ile modifiye edilmiş kitosan/polivinil alkol biyokompozitleri mikro kirleticilerin giderimi amaciyla yeni ve yenilikçi bir yaklaşım olarak adsorpsiyon işlemlerinde kullanılabilir.

\section{Teșekkür}

Sunulan bu çalışmadaki analizler ve kimyasal alımları, Yalova Üniversitesi Bilimsel Araştırma Projeleri 2016/DR/002 no'lu projeden alınan destekle gerçekleştirilmiştir.

\section{Kaynaklar}

[1] Yuana H., Zhanga J., Lua, Z., Mina H., Wuc C. 2009. Studies on Biosorption Equilibrium And Kinetics of $\mathrm{Cd}^{2+}$ by Streptomyces Sp. K33 and HL-12. Journal of Hazardous Materials, 164: 423431.

[2] Onyancha D., Ward Mavura W., Ngila J.C., Ongoma P., Chacha J. 2008. Studies of Chromium Removal from Tannery Wastewaters By Algaebiosorbents, Spirogyra Condensata and Rhizoclonium Hieroglyphicum. Journal of Hazardous Materials, 158: 605-614.

[3] Erdogan Y.A. 2005. Atık Sulardan Çeşitli Adsorpbanlarla Arsenik Giderimi. İstanbul Teknik Üniversitesi, Fen Bilimleri Enstitüsü, Yüksek Lisans Tezi, 136s, İstanbul.

[4] Othmer K. 2008. Seperation Technology. John Wiley \& Sons Inc, 2nd Ed, Vol.1, USA.

[5] Özçimen D. 2007. Çeşitli Bitkisel Atıkların Karbonizasyon Yoluyla Değerlendirilmesi. İstanbul Teknik Üniversitesi, Fen Bilimleri Enstitüsü, Doktora Tezi, 223s, İstanbul.

[6] Kumar M., Kulshreshtha J., Singh G.P. 2011. Growth and Biopigment Accumulation of Cyanobacterium Spirulina Platensis at Different Light Intensities and Temperature. Brazilian Journal of Microbiology, 42 (3): 1128-1135.

[7] Madkour F.F., Kamil A.E.W., Nasr H.S. 2012. Production and Nutritive Value of Spirulina Platensis in Reduced Cost Media. The Egyptian Journal of Aquatic Research, 38 (1): 51-57.

[8] Bilgin Simsek E., Saloglu D., Ozcan N., Novak I., Berek D. 2017. Carbon Fiber Embedded Chitosan/PVA Composites for Decontamination of Endocrine Disruptor Bisphenol-A from Water. Journal of the Taiwan Institute of Chemical Engineers, 70: 291-30.

[9] Saloglu D., Ozcan N. 2018. Activated Carbon Embedded Chitosan/Polyvinyl alcohol Biocomposites for Adsorption of Nonsteroidal Anti-inflammatory Drug-Naproxen from Wastewater. Desalination and Water Treatment, 107: 72-84.

[10] Kanmaz N., Saloglu D., Hizal J. 2019. Humic Acid Embedded Chitosan/Poly (Vinyl Alcohol) pH Sensitive Hydrogel: Synthesis, Characterization, Swelling Kinetics and Diffusion Coefficient, Chemical Engineering Communications, 206 (9): 1168-1180.

[11] Jung C., Oh J., Yoon Y. 2015. Removal of Acetaminophen and Naproxen by Combined Coagulation and Adsorption Using Biochar: Influence of Combined Sewer Overflow Components. Enviromental Science and Pollution Research, 22 (13): 10058-10069.

[12] Ozdemir Ç., Önal Y., Erdoğan S., Başar C. 2012. Studies on Removal of Naproxen Sodium by Adsorption onto ACF in Batch and Column. Fresenius Ennviromental Bulletin, 21 (1): 84-93.

[13] Khazri H., Ghorbel-Abid I., Kalfat R., Ayadi M. 2017. Removal of Ibuprofen, Naproxen and Carbamazapine in Aqueous Solution onto Natural Clay: Equilibrium, Kinetics, and Thermodynamic Study. Applied Water Science, 7 (6): 3031-3040.

[14] Bulut Y., Aydin, H. 2005. A Kinetics and Thermodynamics Study of Methylene Blue Adsorption on Wheat Shells. Desalination, 194: 259-267.

[15] Ranganathan K. 2000. Chromium Removal by Activated Carbons Prepared From Casurina Equisetifolia Leaves. Bioresource Technology, 73: 99-103.

[16] Khezami L., Capart R. 2005. Removal Of Chromium (VI) from Aqueous Solution by Activated Carbons: Kinetic and Equilibrium Studies. Journal of Hazardous Materials, 123: 223-231.

[17] Mor S., Ravindra K., Bishnoi N.R. 2007. Adsorption of Chromium from Aqueous Solution by Activated Alumina and Activated Charcoal. Bioresource Technology, 98: 954-957. 
[18] Babel S., Kurniawan T.A. 2004. Cr(VI) Removal from Synthetic Wastewater Using Coconut Shell Charcoal and Commercial Activated Carbon Modified With Oxidizing Agents and/or Chitosan. Chemosphere, 54: 951-967.

[19] Amin T.M., Alazba A., Shafiq M. 2015. Adsorptive Removal of Reactive Black 5 from Wastewater Using Bentonite Clay: Isotherms, Kinetics and Thermodynamics. Sustainability, 7: 15302-15318.

[20] Xin H., Nai-yun G., Qiao-li, Z. 2007. Thermodynamics and Kinetics of Cadmium Adsorption onto Oxidized Granular Activated Carbon. Journal of Environmental Sciences, 19: 1287-1292. 